\title{
Extensive Gastric Atrophy in Patients with Squamous Cell Carcinoma of the Oesophagus: A Descriptive Case Series
}

\section{Kgomo $\mathbf{M}^{*}$, Elnagar A, Nagel $\mathrm{J}$ and Mokoena T}

Faculty of Health Science, Department of Internal Medicine, University of Pretoria, South Africa

"Corresponding author: Kgomo M, Faculty of Health Science, Department of Internal Medicine, University of Pretoria, Steve biko Academic Hospital, Level 9, 31 Bophelo rd gezina, Pretoria, South Africa, Tel: +27123542246; Fax: +27123220696; E-mail: kgomomk@worldonline.co.za

Received date: June 21, 2016; Accepted date: July 20, 2016; Published date: July 25, 2016

Copyright: ( $2016 \mathrm{Kgomo} \mathrm{M}$, et al. This is an open-access article distributed under the terms of the Creative Commons Attribution License, which permits unrestricted use, distribution, and reproduction in any medium, provided the original author and source are credited.

\section{Abstract}

Recent studies in Sweden and Japan have reported that extensive gastric atrophy is associated with an increased risk for oesophageal squamous cell carcinoma. They also mentioned that this findings need to be confirmed in other ethnic groups due to the wide geographic variation of this cancer.

Objectives: To determine the prevalence of extensive gastric atrophy in patients with squamous cell carcinoma of the oesophagus over a two year period.

Method: Fifty nine patients with squamous cell carcinoma of the oesophagus referred to gastroenterology division for dilatation or stenting had four additional biopsies taken from the gastric antrum and corpus. This were then evaluated for the presence gastric atrophy and Helicobacter pylori by an experienced histopathologist.

Results: Extensive gastric atrophy defined as atrophy of both the antrum and the corpus was found in $15(25 \%)$ of the fifty nine patients. Nine $(60 \%)$ of these patients were also positive for Helicobacter pylori by methylene blue.

Conclusion: The prevalence of extensive gastric atrophy in these patients with squamous cell carcinoma of the oesophagus is much lower than that found in Sweden and Japan, i.e. less than half of these two regions and the majority of them were found to be infected by $h$ pylori. . This suggest that even though extensive gastric atrophy is an important factor in certain areas, it may be less important of a factor in South Africa and other geographic areas as shown in other studies. This still need to be investigated further in larger studies to fully understand the role of extensive gastric atrophy in these patients.
\end{abstract}

Keywords: Gastric atrophy; Squamous cell carcinoma; Cancer; Oesophagus; Gastric antrum

\section{Introduction}

The incidence of oesophageal cancer varies widely in the world. In the Middle East, Africa, and Asia and parts of Europe, Squamous cell carcinoma of the eoesophagus dominates the oesophageal cancer landscape. Worldwide the rates are highest in Northern China, South Africa, Turkey and Iran.1 In the United States, the black population has a five-fold higher incidence of OSCC than the white population [1]. A recent study in Sweden has reported that gastric atrophy is associated with an increased risk for oesophageal squamous cell carcinoma [2].

A similar study in Japan reported that extensive gastric atrophy is associated with a two to three fold increase risk for oesophageal squamous cell carcinoma $[2,3]$.

Several meta-analysis looked at the relationship between gastric atrophy and oesophageal squamous cell carcinoma (OSCC) and showed conflicting results from different regions [4].

Histology is the gold standard for diagnosing gastric atrophy [5]. Oesophageal squamous cell carcinoma is the eighth most common cause of cancer related death worldwide [5].
The highest mortality rate of OSCC are found in East Asia, Southern and Eastern Africa where patients present late [6].

Many epidemiological studies have consistently shown heavy alcohol drinking and tobacco smoking to be main risk factors for OSCC $[2,4]$.

This cancer usually presents too late for curative therapy and attempts to identify as many risk factors as possible may help in detecting OSCC early enough for curative therapy.

There are no studies done locally to determine the relationship between gastric atrophy and OSCC, a common cancer in the South African populations.

A study done in Latin America found no association between gastric atrophy and OSCC in Latin American population [7].

We performed a prospective descriptive histological case series study over a two year period to determine the prevalence of extensive gastric atrophy in patients with oesophageal squamous cell carcinoma [8]. 


\section{Method}

Consecutive patients with OSCC referred to gastrointestinal division of Steve Biko Academic Hospital for oesophageal stenting or balloon dilatation were recruited.

A written informed consent for taking four additional biopsies from the gastric Antrum and the corpus was obtained. Two biopsy specimen each were taken from mid antrum and upper body by experienced gastroenterologists in our department.

These biopsies were then examined by an experienced histopathologist for gastric atrophy, metaplasia dysplasia and with methylene blue staining for the presence of $H$. pylori. Extensive gastric atrophy was defined as atrophy involving both the antrum and the corpus.

All patients had advanced incurable cancer with only palliative therapy possible.

\section{Results}

Fifty nine patients ranging in age from 27 to 87 were recruited. They consisted of forty five males and fourteen females. All patients were from South Africa.

The racial distribution was 54 black South Africans and 5 Caucasians. Of the 59 subjects with OSCC, only 15 were found to have extensive gastric atrophy described as atrophy of both the gastric antrum and corpus giving us $25 \%$ prevalence. Helicobacter pylori was found in $9(60 \%)$ of these patients.

The binomial exact confidence interval was $95 \%$.

\section{Conclusion}

The prevalence of extensive gastric atrophy in our patients was found to be much lower than the Japanese and the Swedish groups but similar to the Latin American studies and the majority of it was found to be associated with Helicobacter pylori infection. This may suggest that extensive gastric atrophy is an important factor depending on the geographic area studied.

\section{Discussion}

The prevalence of extensive gastric atrophy in our patients with oesophageal squamous cell carcinoma during this period is much lower, less than half of the Japanese and Swedish study groups, but is similar to other studies done previously in other regions as indicated in various meta-analysis and the Latin American study. In this study however, histology was the only method used to detect extensive gastric atrophy because of cost constraints. The number of biopsies was increased to improve accuracy. Helicobacter pylori was found in most of these patients which could be co incidental or important cause as we leave in an area with a high prevalence of infection.

Our study has smaller sample size compared to Swedish and the Japanese study, and was conducted over a short period of two years only however, our patients had more advanced disease which were not curable at presentation and It is these patients that extensive gastric atrophy would be expected. A retrospective study to increase sample size could not be done because gastric atrophy is not routinely looked for in the care of these patients as it has no influence on further therapy.

This study also shows that OSCC is more common among black South Africans especially male patients and is a disease of adults increasing in prevalence with age. This may indicate that other risk factors other than extensive gastric atrophy play an important role as all races are exposed to $H$. pylori which is a known cause of gastric atrophy in this country.

More studies with larger sample size are needed to clearly define this relationship as we still get conflicting result from different regions (Table 1).

\begin{tabular}{|l|l|l|l|l|l|}
\hline \multicolumn{7}{|c|}{ Total Number of Cases N=59 } \\
\hline Gender & Race & & \\
\hline Male & Female & Black & $\begin{array}{l}\text { Caucasi } \\
\text { an }\end{array}$ & + EXT G/A & H. pyloripos \\
\hline 45 & 14 & 54 & 5 & 15 & 9 \\
\hline $76 \%$ & $23 \%$ & $91 \%$ & $9 \%$ & $25 \%$ & $60 \%$ \\
\hline Index: EXT G/A=Extensive gastric atrophy.
\end{tabular}

Table 1: Prevalence of extensive gastric atrophy in OSCC.

\section{References}

1. Leichman L, Thomas C (2011) Squamous cell Cancer of the Esophagus: The Forgotten One, Gastrointestinal Cancer Research 4: 22-23.

2. Iijima K, Koike T, Abe Y (2007) Extensive Gastric Atrophy: An Increased Risk Factor for Superficial Esophagel Squamous Cell Carcinoma in Japan. Amerian Journal of Gastroenterology 102: 1603-1609.

3. Wynder EL, Bross IJ (1961) A Study of etiological factors in cancer of the esophogus. Cancer 14: 389-413.

4. Turati F, Galeone C, La Vecchia C (2011) Coffee and Cancers of the upper digestive and respirotary tracts: Matter analysis of observational studies. Annal Oncol 22: 536-544.

5. Asrollahzadeh D, Kamanga F, Aghcheli K (2008) Tobacco and alcohol use in relation to oesophageal squamous cell carcinoma in a high risk area of Iran. Br J Cancer 98: 1857-1863.

6. Almodova E, Oliveira W (2013) Atrophic Gastritis: Risk factor for esophageal squamous cell carcinoma in a Latin-American population. World J Gastroenterol 19: 2060-2064.

7. Ye W, Held M, Lagergren J (2004) Helicobacter pylori infection and gastric atrophy: risk of adenocarcinoma andsquamous cell carcinoma of the esophagus and adenocarcinoma of gastric cardia, J Natl Cancer Inst 96: $388-396$

8. Nasrollahzadeh D, Maleksadeh R, Aghcheli (2012) Gastric atrophy and oesophageal squamous cell carcinoma: possible interaction with dental health and oral hyagine habit. Br J Cancer 107: 888-894. 